take four days each way. I am afraid, however, that it might prove very difficult to secure any sample of this stone for transportation to Europe. AlfFred Tingle.

Chinanfu, Shantung, China, November 9, 1905.

\section{Auroræ of November 15 and December 12.}

Since my communication of December 9 (NATURE, December 28), I have learned that the aurora borealis of November, 15 was observed here by several persons between 8.30 p.m. and 9.30 p.m., Halifax time. The appearances were similar to those noted in England (Nature, November 23, pp. 79-80), and the rosy-red streamers seem to have attracted special attention.

I am also informed that an aurora was observed here last night (December I2) at 9.30 p.m. with whitish streamers, but lacking the display of colour observed November 15

It is somewhat noteworthy that the interval November I5 $_{5}$ to December 12 covers a period of twenty-seven days-the time required for one complete rotation of the sun.

Alexander Graitam Bell.

Beinn Bhreagh, near Baddeck, Nova Scotia,

December 13, 1905.

The Principles of Heredity.

I HAVE every reason to be satisfied with the kind and indulgent review (December 7, p. 12x) by "A. D. D." of my book "The Principles of Heredity," but there is one sentence of it on which I should like to comment, more particularly as it contains nothing of blame or praise. "A. D. D." writes, "this book ... is an embodiment of the recognition by medical men that they depend ultimately for a precise knowledge of nature on the professional biologist-who may or may not, at the same time, be a medical man.'

But really $I$ do not think that. On the contrary, I believe it is easily capable of demonstration that the information already in the hands of all medical men is incomparably superior, both in precision and volume, to anything ever possessed, or likely to be possessed, by biologists. It has not been utilised, that is all. The blame does not rest wholly with the medical man. His strictly professional curriculum is burdened by a monstrous but necessary load of facts. His one chance of coming in contact with subjects of general interest and of acquiring habits of sustained and accurate thought lies in the purely scientific part of his curriculum. Here his teachers are biologists who, instead of inculcating wide principles of heredity and evolution, add to the load on his memory by supplying irrelevant scraps of information about jelly-fish, earthworms, cockchafers, and the like-irrelevant, for, in the form they are presented, they do not link up with the studies and interests of his future career, and therefore are forgotten as soon as may be. "A. D. D." complains that I do not sufficiently appreciate classical teaching. It may console him to know that my appreciation of a certain class of scientific teaching is just as-well, hearty.

The biologist has surpassed the medical man in the study of great problems only because his attention has been directed to the subject, and because, on the whole, his habits of thought--not information-have been more precise. Had the medical man received the training of the biologist, or the biologist possessed the information common to medical men, the progress of science would have been much more rapid, and few or none of the great biological controversies of the past would have arisen, or at least have endured the interminable time they did; for example, the disputes as to whether natural selection is the cause or the sole cause of evolution, as to whether acquired characters are transmissible, as to whether variations are due to the direct action of the environment, as to whether evolution proceeds on lines of "fluctuating" variations or of discontinuous "mutations," as to the function of sex, and so forth.

Of necessity we-that is, all men-know the human type better than we can possibly know any other. Provided we know what to look for, extreme familiarity enables us to observe the smallest variations. No shepherd knows his flock, no biologist knows animal or plant as NO. I 888, VOL. 73] the medical man knows his fellow man. The species has diverged into a large number of natural varieties, dwelling under immensely diverse conditions and differing vastly in every peculiarity of body and mind. All these varieties, apparently, are inter-fertile, and almost all of them, in bulk or in isolated cases, have crossed with almost every other variety. Hybrids are being reared every day, and many races are compound hybrids-e.g. the CaucasianNegro-Indian inhabitants of parts of South America. Above all, the species is being stringently selected and is undergoing rapid evolution under the action of disease, an agency which furnishes the most perfect series of experiments in heredity and evolution imaginable. Every race is resistant to every disease strictly in proportion to its past experience of it. Some diseases are short and sharp, others are of long duration. Some are local, others fill the whole system with micro-organisms or bathe the germcells with toxins. Many diseases are new to many races; others they have afflicted for thousands of years. If ever acquirements are transmitted, however "faintly and fitfully," it should be in the case of disease. If ever variations, no matter how small, are caused by the direct action of the environment, a race long afflicted should show the trace. If Mendelian phenomena play an important part in nature, we should note them in crossed varieties of men. If evolution proceeds on lines, not of fluctuating variations, but of stable mutations "which only selection can eliminate," then races (e.g. British) which have become highly resistant to this or that disease (e.g. consumption) should not constantly produce individuals who are as susceptible as members of a race which has undergone no such evolution (e.g. Red Indian).

Unless heredity in man differs from heredity in other species, it is very evident that medical men have no need to go to biologists for precise information, but that there is every need that biologists should go to medical men. $A$ vast fund of minutely accurate data, much of which is statistical, is available. To grope in the obscurity that necessarily surrounds the past and the present of wild species or amid the confusion of the unrecorded crosses of domesticated varieties while this fund is untouched may be magnificent, but it is not science.

Southsea, December II, 1905 .

G. Archdall Reid.

Dr. REID takes exception to a passage in my review of his book; in it I state my belief that his book is the embodiment of a certain opinion, but Dr. Reid writes to say that he does not hold this view at all. It is not necessary, nor would it be profitable if it were, to discuss who is right in this matter-he or I-for obviously I am guilty of misrepresenting Dr. Reid's opinion.

But that the medical man is capable of acquiring a precise knowledge of nature independently of the information already gained and the methods employed by the biologist does not seem to me to be by any means certain. Dr. Reid thinks it is, and brings forward as evidence the fact that doctors possess better data for the solution of problems of evolution than ever have been, or can be, possessed by the biologist. Now, even supposing this to be true-which I do not for a moment-it does not seem to me to prove Dr. Reid's point. Either he thinks that the possession of data is tantamount to a precise knowledge of nature, or he does not; if he does, he proves his point by introducing into his syllogism a premiss which I believe to be untrue; if he does not-and I do not believe that he does-he does not prove his point.

But he this as it may, the point that interests me is that the belief that there is no great step between the collection of data and the derivation from them of a precise knowledge of nature is a widespread and, I believe, a profoundly erroneous one; for it seems to me that the possession of data is a small advance towards such a precise knowledge, and that that which hinders the acquisition of natural knowledge is not the slowness with which facts are accumulated, but the paucity of investigators capable of dealing with them properly; and this dearth is due to the infection of the majority of biologists by a disease-a sort of sleeping sickness-which consists in a disinclination to picture to the mind's eye the things represented by the words they use.

Let us proceed to examine Dr. Reid's main thesis-that 